\title{
Gerakan Bersama Kenali, Cegah, dan Atasi Stunting Melalui Edukasi Bagi Masyarakat di Desa Padamara Kabupaten Purbalingga
}

\section{A Movement To Recognize, Prevent, and Overcome Stunting Through Education For The Community in Padamara Village, Purbalingga Regency}

\author{
${ }^{1)}$ Mustika Ratnaningsih Purbowati*, ${ }^{2)}$ Ira Citra Ningrom, ${ }^{3)}$ Ratna Wulan Febriyanti \\ ${ }^{1,2,3)}$ Program Studi Pendidikan Dokter, Fakultas Kedokteran, Universitas Muhammadiyah Purwokerto \\ Email: mustikaratnaningsih@gmail.com
}

\begin{abstract}
Abstrak
Balita yang mengalami kekurangan gizi dalam jangka waktu lama terutama dalam 1000 hari pertama kehidupan dapat mengalami kegagalan pertumbuhan atau biasa disebut stunting. Indonesia memiliki target menurunkan angka kejadian pada angka 14\% pada tahun 2024. Pemerintah dan seluruh masyarakat harus berperan serta dalam upaya pencapaian target tersebut. Edukasi secara berkelanjutan dinilai dapat menjadi salah satu cara untuk menurunkan angka stunting. Kegiatan ini memiliki tujuan meningkatkan pengetahuan masyarakat meliputi remaja, ibu hamil, dan kader Posyandu agar dapat mengenali stunting, mengetahui upaya pencegahan, dan penatalaksanaan stunting. Metode yang digunakan dalam kegiatan ini melalui kegiatan webinar yang berisi materi cara mengenali stunting, cara menilai status gizi yang benar menggunakan KMS (Kartu Menuju Sehat) terbaru, pentingnya 1000 hari pertama kehidupan, cara pencegahan stunting, dan apa yang harus dilakukan ketika menjumpai stunting. Materi diberikan kepada 25 peserta selama 120 menit. Tingkat pengetahuan peserta diukur sebelum dan sesudah kegiatan melalui pretest dan postest. Kegiatan ini berhasil meningkatkan pengetahuan masyarakat. Hasil pretest didapatkan 5 peserta (20\%) memiliki pengetahuan baik, 7 peserta (28\%) memiliki pengetahuan sedang, dan 13 peserta (52\%) memiliki pengetahuan kurang. Tingkat pengetahuan meningkat setelah pemberian materi dan sesi tanya jawab yaitu terdapat 22 peserta (88\%) memiliki pengetahuan baik, dan 3 peserta (12\%) memiliki pengetahuan sedang. Seluruh komponen masyarakat diharapkan dapat ikut berperan serta aktif dalam upaya menurunkan angka kejadian stunting.
\end{abstract}

Kata Kunci: edukasi, pengetahuan masyarakat, stunting

\begin{abstract}
Toddlers who experience malnutrition for a long time, especially in their first 1000 days of life may result in growth failure or commonly called stunting. Indonesia has a target of reducing the incidence rate to $14 \%$ by 2024 . The government and the entire community must participate to achieve this target. Sustainable education is considered to be one way to reduce stunting rates. This activity has the aim of increasing public knowledge including adolescents, pregnant women, and Posyandu cadres so that they can recognize stunting, know how to prevent, and manage stunting. The method used in this activity is through a webinar that contains material on how to recognize stunting, how to assess the correct nutritional status using the latest KMS (Health Record Book), the importance of the first 1000 days of life, how to prevent stunting, and what to do when encountering stunting. The material was given to 25 participants for 120 minutes. The level of knowledge of participants was measured before and after the activity through pretest and posttest. This activity succeeded in increasing public knowledge. The results of the pretest showed that 5 participants (20\%) had good knowledge, 7 participants (28\%) had moderate knowledge, and 13 participants (52\%) had poor knowledge. The level of knowledge increased after giving the material and the question and answer session, namely 22 participants (88\%) had good knowledge, and 3 participants (12\%) had moderate knowledge. All components of society are expected to participate actively to reduce the incidence of stunting.
\end{abstract}

Keywords: education, public knowledge, stunting 


\section{Pendahuluan}

Kekurangan gizi dalam jangka waktu lama terutama pada seribu hari pertama kehidupan dapat menimbulkan kegagalan pertumbuhan. Anak yang mengalami hal tersebut terlihat lebih pendek dibandingkan anak seusianya. Kondisi ini biasa disebut dengan stunting. Tiga dari sepuluh anak balita mengalami Stunting (UNICEF, 2018). Data Dinas Kesehatan Kabupaten Purbalingga menyebutkan terdapat 71.121 balita dan yang rutin melakukan penimbangan adalah 60.358 balita (84,9\%). Jumlah balita gizi kurang adalah 2.401 (4\%) sedangkan kasus gizi buruk terdapat 56 kasus dan semua telah mendapatkan penanganan perawatan. (Dinas Kesehatan Purbalingga, 2019). Kementerian Kesehatan mentargetkan angka stunting turun dari 27,7\% menjadi 14\% di dalam RPJMN tahun 2020 hingga tahun 2024.(Kementerian Kesehatan, 2020)

Pemerintah menetapkan lima pilar penangan stunting antara lain kepemimpinan yang memiliki visi dan komitmen, edukasi secara nasional yang akan menimbulkan perubahan perilaku, program yang terintegrasi di semua tingkat pemerintahan, pangan dan gizi yang baik, serta monitoring dan evaluasi secara berkelanjutan untuk mencapai target tersebut. Lima pilar tersebut di jabarkan dalam banyak upaya yang terdiri dari upaya gizi spesifik dan gizi sensitive. Upaya ini harus dilakukan secara terintegrasi agar dapat mencapai hasil maksimal. (Kementerian Kesehatan, 2020). Upaya gizi spesifik memiliki sifat jangka pendek dan langsung ditujukan pada seribu hari pertama kehidupan. Upaya gizi sensitif memiliki sifat jangka panjang dan ditujukan kepada masyarakat luas tidak hanya pada seribu hari pertama kehidupan. Edukasi dengan tujuan meningkatkan pengetahuan merupakan salah satu upaya sensitif yang dapat dilakukan (Warta Kesmas, 2018)

Berdasarkan berbagai hasil penelitian didapatkan bahwa terdapat banyak faktor yang mempengaruhi kejadian stunting. Salah satu faktor tersebut adalah pengetahuan. Tingkat pendidikan ibu, pengetahuan ibu tentang gizi, pendapatan keluarga, pemberian ASI eksklusif, usia mendapatkan makanan tambahan ASI, kecukupan mikronutrien seperti zinc dan zat besi, riwayat penyakit infeksi, serta faktor genetik disebut berpengaruh terhadap stunting baik di pedesaan dan perkotaan (Rohmawati, 2015; Wulandari, Muniroh,2020). Gizi sangatlah penting bagi proses pertumbuhan dan perkembangan anak. Kecukupan gizi bisa didapatkan dengan mengkonsumsi beragam makanan, maka pengetahuan ibu tentang gizi menjadi hal yang sangat penting bagi pencegahan dan penanganan stunting (Rahmandiani et al, 2019). 
Untuk mencapai target penurunan angka stunting dibutuhkan kerjasama berbagai pihak meliputi pemerintah baik pusat maupun daerah, akademisi, bahkan unsur masyarakat dan keagamaan. Mitra kegiatan pengabdian kepada masyarakat, yaitu Desa Padamara membutuhkan peran semua elemen masyarakat tidak terkecuali akademisi untuk meningkatkan pengetahuan dan kesadaran keluarga. Kader sebagai bagian terdekat dengan masyarakat memiliki peran penting sebagai agen perubahan pengetahuan, sikap dan perilaku sehingga dapat menurunkan prevalensi stunting di wilayah tersebut. Kegiatan ini memiliki tujuan meningkatkan pengetahuan masyarakat meliputi remaja, ibu hamil, dan kader Posyandu agar dapat mengenali stunting, mengetahui upaya pencegahan, dan penatalaksanaan stunting.

\section{Metode}

Kegiatan pengabdian kepada masyarakat ini dilaksanakan melalui kegiatan webinar dengan memberikan penjelasan tentang cara mengenali, mencegah, dan mengatasi stunting. Kegiatan dilaksanakan secara online sehingga peserta dapat mengikuti dari tempat masing masing. Media yang digunakan antara lain video, leaflet, dan power point. Materi meliputi cara mengenali stunting, cara menilai status gizi yang benar menggunakan KMS (Kartu Menuju Sehat) terbaru, pentingnya seribu hari pertama kehidupan, cara pencegahan stunting, dan apa yang harus dilakukan ketika menjumpai stunting. Materi diberikan kepada 25 orang peserta yang terdiri dari remaja, ibu hamil, dan kader Posyandu dengan durasi 120 menit. Sebelum dan sesudah mengikuti kegiatan peserta mengikuti pretest dan postest. Distribusi data meliputi karakteristik sosiodemografi, serta tingkat pengetahuan peserta sebelum dan sesudah mengikuti kegiatan didapatkan memalui analisis univariat

\section{Hasil Dan Pembahasan}

\section{Distribusi Frekuensi Karakteristik Sosiodemografik}

Berdasarkan Tabel 1, dapat diketahui bahwa usia peserta kegiatan cukup homogen, mencakup rentang usia 17 hingga 19 tahun, dan diatas 30 hingga 35 tahun. Pesera berusia 17 hingga 19 tahun sebanyak 5 orang (20\%) dan peserta berusia 30 hingga 35 tahun sebanyak 20 orang $(80 \%)$. Tingkat pendidikan peserta kegiatan meliputi SMP sebanyak 2 orang (8\%), SMA 18 orang (72\%), dan S1 / S2 sebanyak 7 orang (28\%). Pekerjaan peserta kegiatan cukup bervariasi diantaranya pelajar sebanyak 5 orang $(20 \%)$, ibu rumah tangga sebanyak 14 orang (16\%), guru sebanyak 3 orang (12\%), dan dosen sebanyak 3 orang (12\%). 

SYIFA

Tabel 1. Distribusi Frekuensi Karakteristik Sosiodemografik

\section{Karakteristik}

Sosiodemografik

Usia

$$
\begin{aligned}
& 17-19 \text { tahun } \\
& 30-35 \text { tahun }
\end{aligned}
$$
Jumlah

(n)

\section{Persentase}

(\%)

\section{Tingkat pendidikan}

SMP

SMA

$\mathrm{S} 1 / \mathrm{S} 2$

\section{Pekerjaan}

Pelajar

Ibu rumah tangga

Guru

Dosen
2

18

7

\section{Distribusi Frekuensi Tingkat Pengetahuan}

Berdasarkan Tabel 2 dapat diketahui bahwa tingkat pengetahuan peserta kegiatan sebelum mendapatkan pemaparan materi dan mengikuti sesi diskusi adalah sebanyak 13 orang (52\%) memiliki tingkat pengetahuan kurang, sebanyak 7 orang (28\%) memiliki tingkat pengetahuan sedang, dan sebanyak 5 orang (20\%) memiliki tingkat pengetahuan baik. Tingkat pengetahuan ini meningkat setelah peserta mendapatkan pemaparan materi dan mengikuti sesi diskusi yaitu tidak ada peserta yang memiliki tingkat pengetahuan kurang (0\%), sebanyak 3 orang (12\%) memiliki tingkat pengetahuan sedang, dan sebanyak 22 orang (88\%) memiliki tingkat pengetahuan baik.

Tabel 2. Distribusi Frekuensi Tingkat Pengetahuan

\begin{tabular}{lcccc}
\hline \multicolumn{1}{c}{ Tingkat } & \multicolumn{2}{c}{ Sebelum Edukasi } & \multicolumn{2}{c}{ Setelah Edukasi } \\
Pengetahuan & Jumlah (n) & Persentase (\%) & Jumlah (n) & Persentase \\
& & & & $(\%)$ \\
Kurang & 13 & 52 & 0 & 0 \\
Sedang & 7 & 28 & 3 & 12 \\
Baik & 5 & 20 & 22 & 88 \\
\hline
\end{tabular}


Edukasi secara terus menerus memberikan efek yang positif terhadap upaya penurunan angka kejadian stunting (Permatasari et al, 2020). Edukasi yang dilakukan dapat meningkatkan tingkat pengetahuan masyarakat. Peningkatan pengetahuan dipengaruhi oleh usia, tingkat pendidikan, pekerjaan, minat, pengalaman, dan sumber informasi. Peserta mendapatkan peningkatan pengetahuan karena minat yang tinggi terhadap informasi yang diberikan, dan sumber informasi berupa penjelasan menggunakan media yang menarik. (Aridiyah et al, 2015). Beberapa penelitian menjelaskan pengaruh dari pengetahuan terhadap stunting antara lain disebutkan terdapat pengaruh gambaran pengetahuan pencegahan stunting pada ibu hamil sebelum dan sesudah diberikan intervensi penyuluhan (Arsiyati, 2019) dan terdapat perbedaan pengetahuan tentang kriteria stunting sebelum dan sesudah diberi penyuluhan. (Wulandari et al, 2020)

Penelitian lain menyebutkan bahwa tingkat pengetahuan ibu mengenai asupan nutrisi pada anak memiliki peranan yang penting untuk mencegah stunting. Ibu harus mengetahui makanan apa yang diberikan ke bayi dimulai pemberian ASI eksklusif, makanan pengganti ASI, dan asupan makan bergizi yang dapat membantu perkembangan fisik dan otak bayi. Faktor utama yang menyebabkan prevalensi stunting (Sinuraya et al, 2020)

Terdapat berbagai metode untuk melakukan edukasi baik yang disampaikan oleh kader ataupun peer group. Disebutkan bahwa terdapat peningkatan signifikan pengetahuan, sikap, dan perilaku di masyarakat melalui metode peer group. Edukasi merupakan upaya strategis untuk mencegah dan mengatasi stunting. Permasalahan stunting harus segera teratasi, karena akan membawa dampak buruk bagi pembangunan Indonesia di masa sekarang dan akan datang. Stunting merupakan indikator kegagalan pertumbuhan dan dapat mengakibatkan gangguan fungsional, terhambatnya perkembangan fisik dan kognitif, terhambatnya perkembangan sosioemosional balita, dan meningkatkan resiko penyakit degenerative (Permatasari et al, 2020).

\section{Kesimpulan dan Saran}

Gerakan bersama kenali, cegah, dan atasi stunting melalui edukasi bagi masyarakat terbukti dapat meningkatkan pengetahuan masyarakat di Desa Padamara, Kabupaten Purbalingga. Berdasarkan hasil kegiatan pengabdian masyarakat yang telah dilakukan, kami memberikan saran agar kegiatan edukasi harus dilakukan secara berkelanjutan dan menyasar seluruh elemen masyarakat. 


\section{Daftar Pustaka}

Aridiyah OF, Rohmawati N, Ririanty M. (2015). Faktor-faktor yang Mempengaruhi Kejadian Stunting pada Anak Balita di Wilayah Pedesaan dan Perkotaan. e-Jurnal Pustaka Kesehatan, vol. 3 No. 1, Januari 2015

Arsiyati Asri Masitha. (2019). Penyuluhan Media Audiovisual Dalam Pengetahuan Pencegahan Stunting Pada Ibu Hamil di Desa Cibatok 2 Cibungbulang. PROMOTOR Jurnal Mahasiswa Kesehatan Masyarakat, Vol.2 No.3, Juni 2019

Beal T.,Tumilowicz .A., Sutrisna.A.,Izwardy.D.,Neufeld.L.M.(2018). A Review Of Child Stunting Determinants Indonesia.http://doi.org/10.1111/mcn.12617

BKKBN. (2019) $1000 \quad$ Hari $\quad$ Pertama

Kehidupan.https://kampungkb.bkkbn.go.id/postSlider/11365/131602

Dinas Kesehatan Kabupaten Purbalingga. (2019). Profil Kesehatan kabupaten Purbalingga Tahun 2019

Kementerian Kesehatan RI. (2018). Warta Kesmas. Cegah Stunting itu Penting. Edisi 2. Tahun 2018. Jakarta

Kementerian Kesehatan RI. (2019). Pencegahan Stunting Pada Anak.https://promkes.kemkes.go.id/

Kementerian Kesehatan RI.(2020). Arah Kebijakan Dan Rencana Aksi Program Kesehatan Masyarakat Tahun 2020 - 2024. http://kemkes.go.id

Permatasari Endah TA, Turrahmi H, Illavina. (2020). Edukasi Gizi Seimbang bagi Kader Posyandu pada Masa Pandemi Covid-19 sebagai Pencegahan Balita Stunting di Kabupaten Bogor. Jurnal As-Syifa Jurnal Pengabdian dan Pemberdayaan Kesehatan Masyarakat. Vol 1. No.2.

Rahmandiani DR, Astuti Sri, Susanti IA, Handayani DS, Didah. (2019). Hubungan Pengetahuan Ibu Balita Tentang Stunting Dengan Karakteristik Ibu dan Sumber Informasi di Desa Hegarmanah Kecamatan Jatinangor Kabupaten Sumedang. Jurnal Sistem kesehatan. Vol. 5 No. 2, Desember 2019.

Rohmawati. (2015). Dalam Astuti Fitria Primi, Purwaningsih Heni. Peningkatan Pengetahuan Masyarakat Tentang Stunting dan Gizi Balita di Desa Rogomulyo Kecamatan Kaliwungu. Indonesian Journal of Community Empowerment (IJCE) Fakultas Ilmu Kesehatan, Universitas Ngudi Waluyo

Sinuraya RK, Qodrina AH, Amalia R.(2019). Peningkatan Pengetahuan Masyarakat Dalam Mencegah Stunting. Jurnal Pengabdian kepada Masyarakat Universitas Padjajajaran. . Vol. 4, No. 2

UNICEF. (2019). The State of the World's Children 2019 Children, food and nutrition https://www.unicef.org/indonesia/state-worlds-children-2019 

SYIFA

World Bank.(2019). Indonesia Accelerates Fight Against Childhood Stunting https://www.worldbank.org/en/news/feature/2018/06/26/indonesiafightsstuntingcommitment-convergence-and-communities

Wulandari CR, Muniroh L. (2020) Hubungan Tingkat Kecukupan Gizi, Tingkat Pengetahuan Ibu, Dan Tinggi Badan Orangtua Dengan Stunting Pada Balita Di Wilayah Kerja Puskesmas Tambak Wedi Surabaya. Amerta Nutrition. Vol 4.No 2. Januari 2020 
